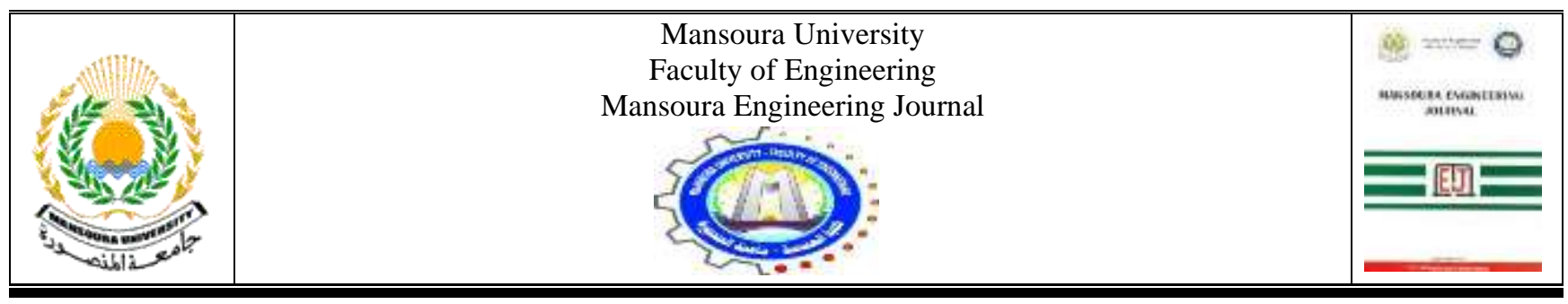

\title{
A new fuzzy logic approach for prediction of surface roughness
}

\author{
Fatma Abdallah Elerian
}

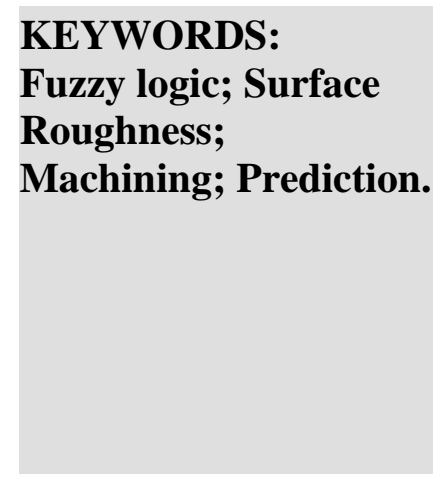

KEYWORDS: Fuzzy logic; Surface Roughness; Machining; Prediction.

\section{INTRODUCTION}

$\mathrm{S}$ URFACE roughness affects significantly the quality of any component. Machining parameters significantly affect Ra value, which is important in many problems such as friction, positional accuracy, contact deformation and so on [1,2].

Titanium material is very expensive and has poor surface finish, low elastic modulus which lead to vibration of tool, so it is cheaper for prediction of its surface roughness under different cutting conditions using modeling and optimization methods [3-6].

Now after many decades many of computerized models such as neural network, genetic algorithms and fuzzy systems [6 - 13] are used to predict surface roughness depending on the experience and skills of machine operator.

Received: (13 June, 2020) - Revised: (30 August, 2020) ) - accepted: (28 September, 2020)

Fatma Abdallah Elerian, Assistant Professor at Production engineering and Mechanical design department, Faculty of engineering, Mansoura university.(e-mail: fatmaelerian@mans.edu.eg)
The prediction of machining parameters effect on Ra during turning of titanium alloy is presented in [6]. This approach indicates good results in comparison with experimental ones.

Genetic Algorithms (GA) are presented in [7] for the optimization of surface roughness and their respective optimal machining parameters. In [8] a surface roughness prediction is done using leave- one- out cross validation (LOO - CV) and an adaptive network- based fuzzy inference system (ANFIS) approach.

A three-layer fuzzy model, genetic programming, radial basis function neural network - fuzzy logic (RBFNN - FL) and adaptive neuro fuzzy inference system (ANFIS) also used for prediction of surface roughness [9-12].

Finally, the computerized models really are very important and give time efficient and cheaper alternative in comparison with time consuming and costly experimental research. A new fuzzy logic approach for predicting values of $\mathrm{Ra}$ is described in this paper. The experimental dataset of turning Ti-6AL-4L [14] is presented in part 2. In part 3 the proposed fuzzy logic is presented. Results and discussion are provided in part 4 followed by the conclusion in part 5 . 


\section{EXPERIMENTAL DATA}

Experimental data for this work was taken from paper [14] Table 1. The authors in [14] studied the effect of cutting parameters (cutting depth, feed and cutting speed) on $\mathrm{Ra}$ during turning a $90 \mathrm{~mm}$ diameter cylindrical solid part and its length is $160 \mathrm{~mm}$ using TaeguTec SRGCR/L 12- 10C tool.

The part is made of Ti6Al-4V alloy. Authors use Taguchi's L27 orthogonal array to conduct the experiments shown in Table 1.

Table 1

Data of 27 experiments using Taguchi's L 27 orthogonal array [14].

\begin{tabular}{|c|c|c|c|c|}
\hline No & $\begin{array}{l}\text { Feed } \\
(\mathbf{m m} / \mathbf{r e v})\end{array}$ & $\begin{array}{l}\text { Cutting } \\
\text { speed } \\
(\mathrm{m} / \mathrm{min})\end{array}$ & $\begin{array}{l}\text { Cutting } \\
\text { depth } \\
(\mathbf{m m})\end{array}$ & $\begin{array}{l}\text { Surface } \\
\text { roughness } \\
\operatorname{Ra}(\mu \mathrm{m})\end{array}$ \\
\hline 1 & 0.06 & 80 & 0.5 & 0.3390 \\
\hline 2 & 0.06 & 80 & 0.75 & 0.3114 \\
\hline 3 & 0.06 & 80 & 1 & 0.2975 \\
\hline 4 & 0.13 & 80 & 0.5 & 0.7532 \\
\hline 5 & 0.13 & 80 & 0.75 & 0.7318 \\
\hline 6 & 0.13 & 80 & 1 & 0.7213 \\
\hline 7 & 0.21 & 80 & 0.5 & 1.5103 \\
\hline 8 & 0.21 & 80 & 0.75 & 1.4932 \\
\hline 9 & 0.21 & 80 & 1 & 1.4764 \\
\hline 10 & 0.06 & 180 & 0.5 & 0.4302 \\
\hline 11 & 0.06 & 180 & 0.75 & 0.4105 \\
\hline 12 & 0.06 & 180 & 1 & 0.4074 \\
\hline 13 & 0.13 & 180 & 0.5 & 0.7611 \\
\hline 14 & 0.13 & 180 & 0.75 & 0.7542 \\
\hline 15 & 0.13 & 180 & 1 & 0.7435 \\
\hline 16 & 0.21 & 180 & 0.5 & 1.5076 \\
\hline 17 & 0.21 & 180 & 0.75 & 1.4956 \\
\hline 18 & 0.21 & 180 & 1 & 1.4892 \\
\hline 19 & 0.06 & 280 & 0.5 & 0.5037 \\
\hline 20 & 0.06 & 280 & 0.75 & 0.4965 \\
\hline 21 & 0.06 & 280 & 1 & 0.4852 \\
\hline 22 & 0.13 & 280 & 0.5 & 0.8967 \\
\hline 23 & 0.13 & 280 & 0.75 & 0.8873 \\
\hline 24 & 0.13 & 280 & 1 & 0.8017 \\
\hline 25 & 0.21 & 280 & 0.5 & 1.6846 \\
\hline 26 & 0.21 & 280 & 0.75 & 1.6754 \\
\hline 27 & 0.21 & 280 & 1 & 1.6687 \\
\hline
\end{tabular}

\section{FUZZY LOGIC APPROACH}

Matlab software fuzzy logic toolbox was used for modeling in this work.

\section{A. Fuzzy logic inference system}

Fuzzy inference systems FIS use fuzzy logic to map data from given input to the output. Fuzzy rule- based system, fuzzy expert system, fuzzy associative memory and fuzzy model are all known as FIS.

The most common types of fuzzy inference methods which will be used in this paper are:

1-. Mamdani method.

2- Sugeno method.

The first method mainly as a rule consequent uses fuzzy set. The second method as a rule consequent uses the input linear function.
The five primary graphical use interface (GUI) tools for constructing, editing, and viewing fuzzy inference system which are used for each one of the above two methods [17] are as following:

1. Editor of FIS.

2. Editor of the membership function.

3. Editor of the rule.

4. Viewer of the rule

5. Viewer of surface.

The stages performed to apply fuzzy logic are:

- fuzzification: used to change a real scalar value into a fuzzy value,

- decision-making: is responsible of the transformation of the input variables to the output ones using the rule-base which is composed of expert IF <antecedents> THEN <conclusions> rules and

- defuzzification: used to produce a quantifiable result in fuzzy logic $[16,18]$.

The quality of fuzzy logic model depends on the membership functions and rules so the more successful selected of them, the more adequate managerial decision.

\section{B. Fuzzy logic surface roughness prediction model.}

In this part of paper to predict Ra, a presentation of how to construct fuzzy logic model will be introduced using two methods (Mamdani and Sugeno). Each method has three inputs of cutting parameters and one single output Ra.

The first method (Mamdani): is used as a fuzzy inference system. The triangle (trimf) function was selected to be combined for the three inputs (cutting speed, feed and cutting depth) and also was selected for the output variable $\mathrm{Ra}$, Figures 1,2,3,4,5.

The centroid method is used with Mamdani fuzzy inference approach for converting the linguistic value shown in Table 2. into the crisp output.

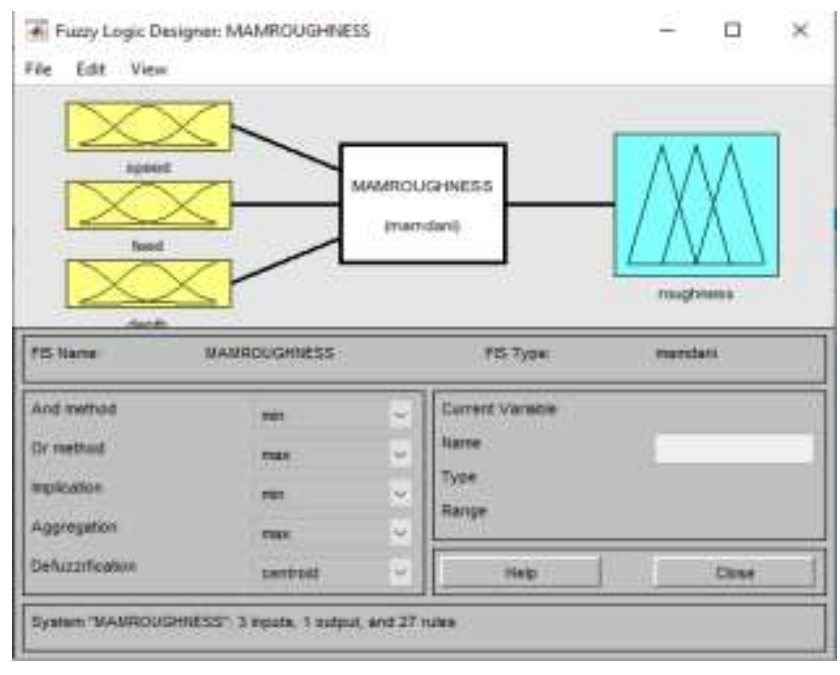

Fig 1. Editor of FIS for the three inputs and one output by Mamdani method. 


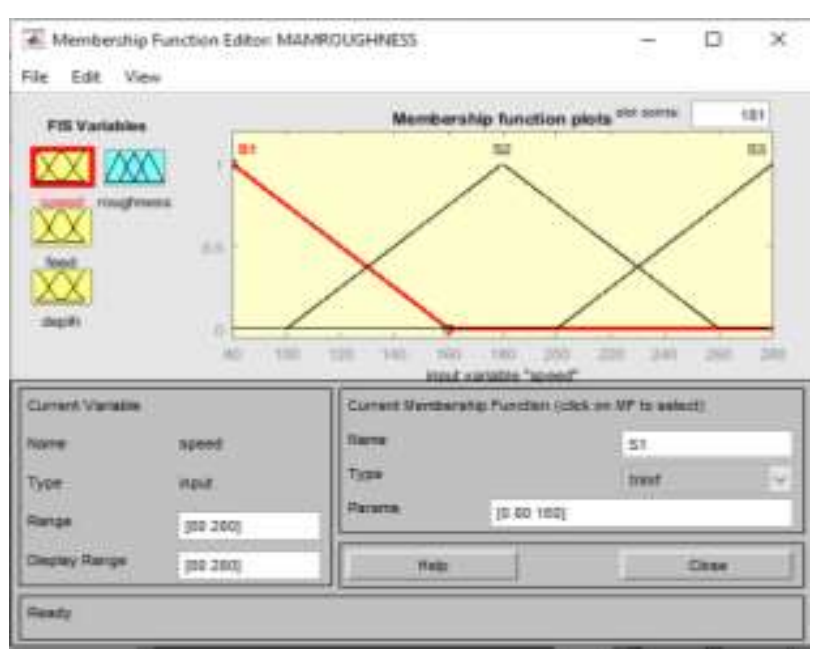

Fig 2. Editor of membership function of input variable: cutting speed (S).

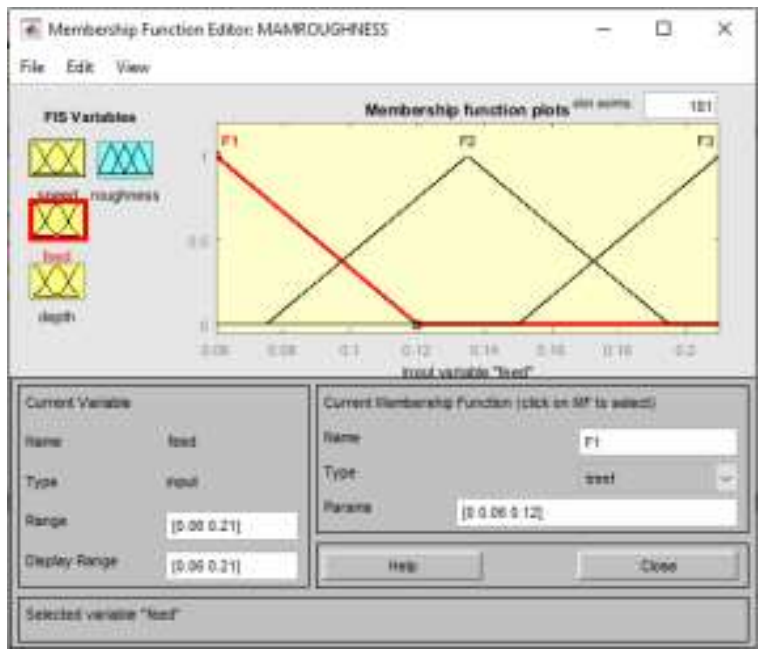

Fig 3. Editor of membership function of input feed (F).

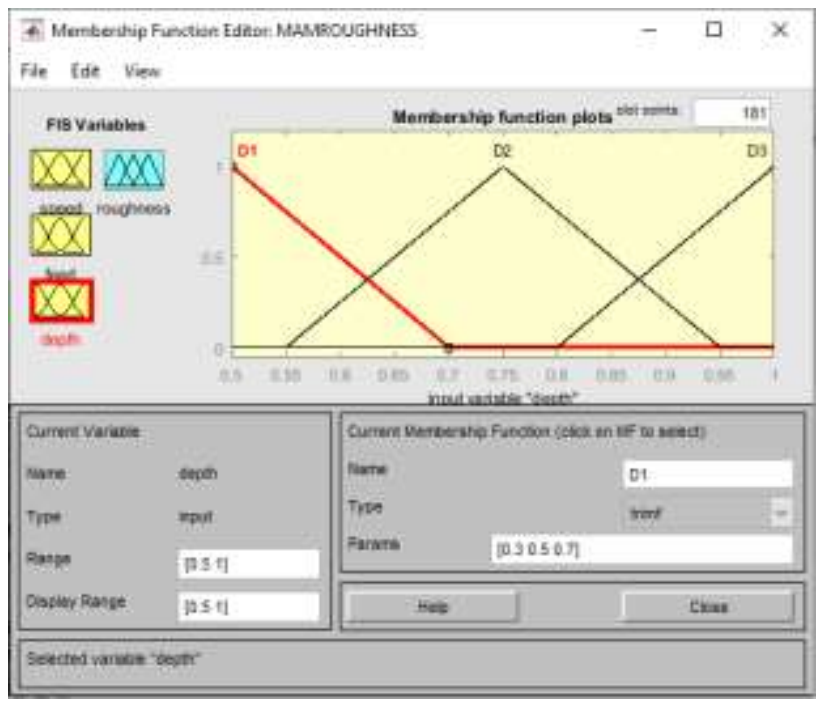

Fig 4. Editor of membership function of input variable: cutting depth (D).

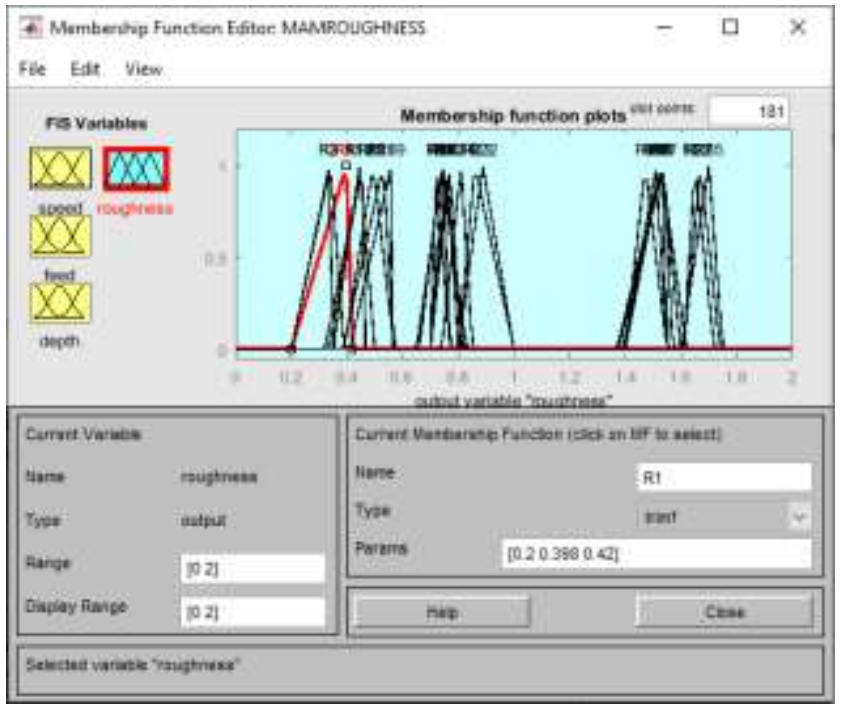

Fig 5. Editor of membership function of output variable: surface roughness.

The linguistic variables of the three inputs are shown in Table 2. Some of FIS rules that were made in rule viewer are shown in Figure 6.

Table 2

Linguistic variables of cutting speed, feed and cutting depth.

\begin{tabular}{|c|c|c|c|c|c|}
\hline \multicolumn{2}{|c|}{$\begin{array}{l}\text { Linguistic variables } \\
\text { of cutting speed }\end{array}$} & \multicolumn{2}{|c|}{$\begin{array}{l}\text { Linguistic variables of } \\
\text { feed }\end{array}$} & \multicolumn{2}{|c|}{$\begin{array}{l}\text { Linguistic variables of } \\
\text { cutting depth }\end{array}$} \\
\hline low & $\mathrm{S} 1$ & Low & F1 & low & D1 \\
\hline medium & $\mathrm{S} 2$ & Medium & $\mathrm{F} 2$ & medium & D2 \\
\hline high & S3 & High & F3 & high & D3 \\
\hline
\end{tabular}

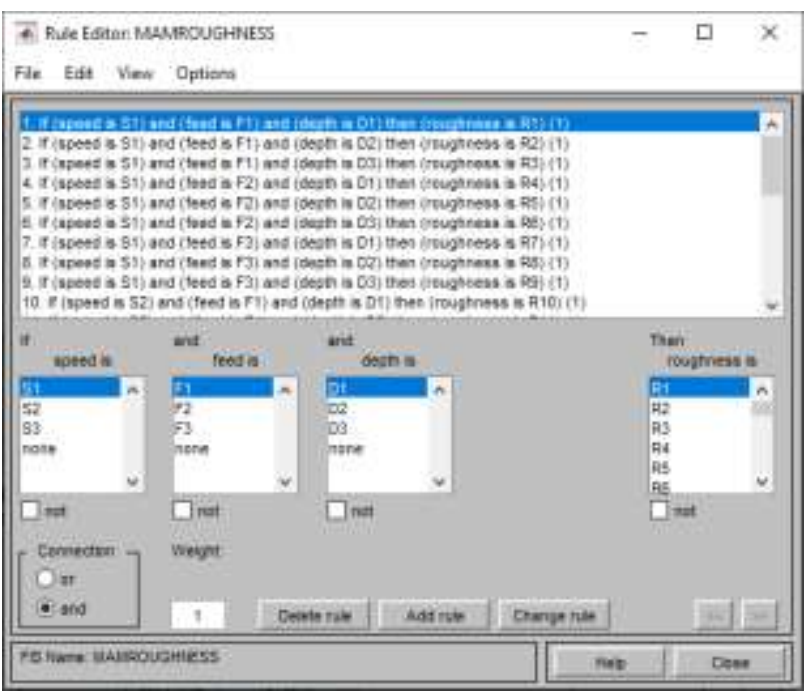

Fig. 6. Editor of FIS rules by Mamdani method.

The Second method (Sugeno): it is like the Mamdani method when constructing the model, but it uses linear function instead of fuzzy set as a rule consequent Figure 7,8,9. 


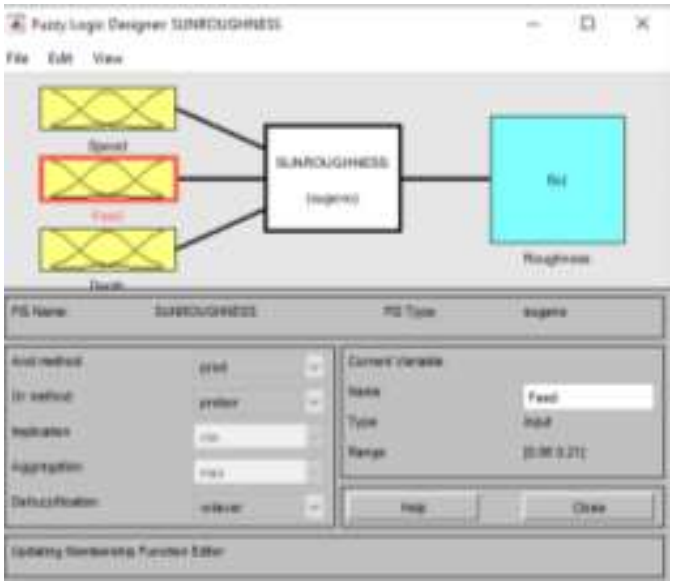

Fig 7. Editor of FIS for the three inputs and one output by Sugeno method.

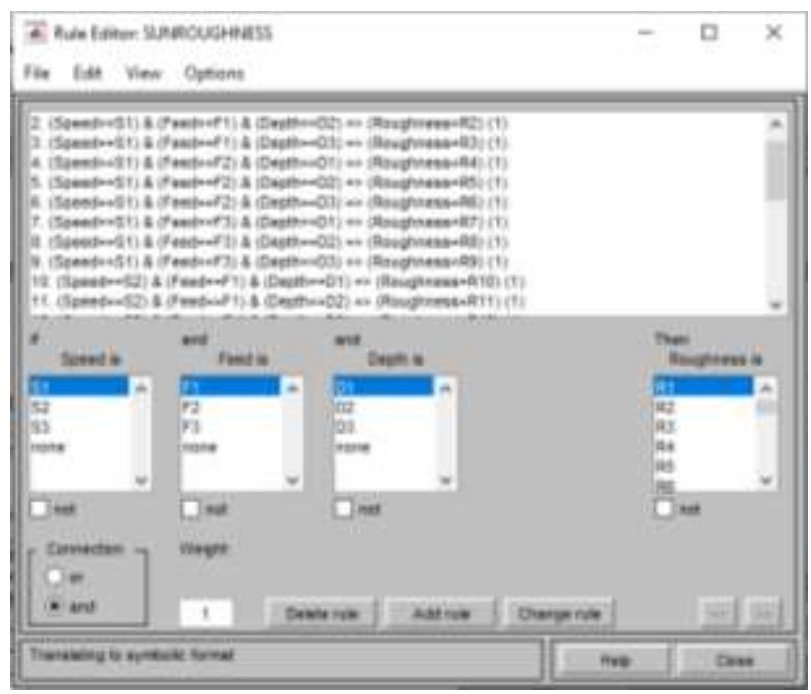

Fig. 8 Editor of FIS rule showing part of rules by Sugeno method.

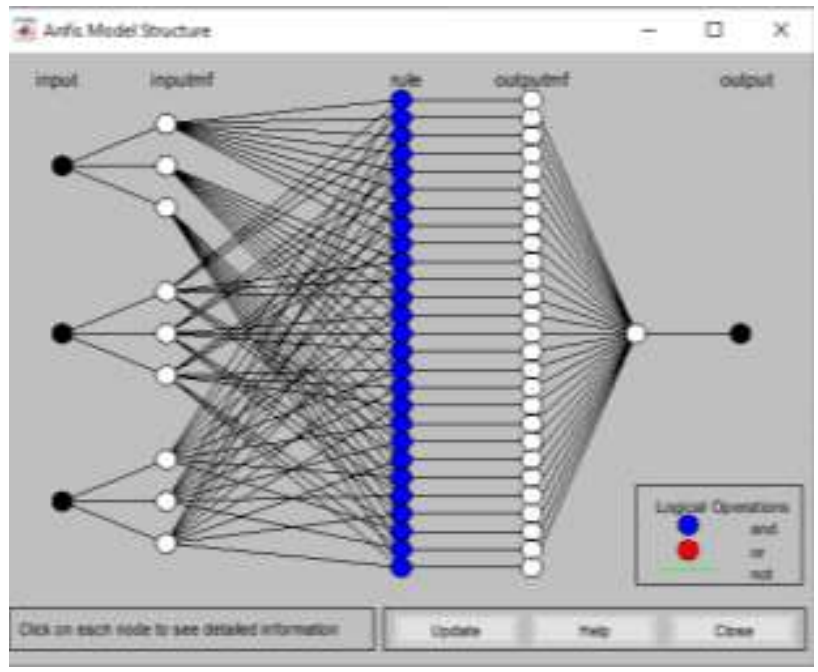

Fig. 9 Structure of Anfis Model by Sugeno method .

\section{RESULTS AND DISCUSSION}

Figures 10,11,12 and Table 3 show the results of applying the fuzzy logic approach using the above two methods. In Figure (12.a) the predicted value of surface roughness using Mamdani method equals $0.755(\mu \mathrm{m})$ for a cutting speed of 180 $\mathrm{m} / \mathrm{min}$, a feed of $0.13 \mathrm{~mm} / \mathrm{rev}$, and a depth of cut of $0.75 \mathrm{~mm}$. And by reviewing the value that corresponds to the cutting conditions mentioned previously in Table 1 . It can be concluded that the expected value gives a good result compared to the experimental one value in Table 1.

The results of the second method (Sugeno) is shown also in Table 3 and Figure 12.b. The predicted value shows again good results with respect to the experimental values in Table 1.

Comparing the results of the proposed model was not limited to comparing it with only the practical results announced in Table 1, but its results were compared with surface roughness theoretical values which obtained by calculating the average value for each of the given inputs (feed, speed and cutting depth) and outputs (surface roughness).

For example: in experiment no 1 and 2 that shown in Table 1 , the average value of speed, feed, cutting depth are $((80+$ $80) / 2=80 \mathrm{~m} / \mathrm{min},(0.06+0.06) / 2=0.06 \mathrm{~mm} / \mathrm{rev},(0.5+$ $0.75) / 2=0.625 \mathrm{~mm}$ ) respectively, the corresponding average value of surface roughness (theoretical) $=(0.3990+0.3114) / 2$ $=0.3252 \mu \mathrm{m}$. The calculated average value of surface roughness (theoretical) also showed good results, this appears in Table 3 in test no. 2,8.

Table no. 3 shows a number of other tests that were performed using the proposed model. Figure.13 shows graphical comparison between predicted value of surface roughness and the experimental \& theoretical ones using the suggested fuzzy logic approach.

Also, Figure 10 indicate that the increase in feed and speed leads to an increase in value of $\mathrm{Ra}$, but there is a difference between the effect of feed and speed on the value of $\mathrm{Ra}$, the effect of feed on $\mathrm{Ra}$ is greater than effect of speed. Also Figure 11 shows that decrease in cutting depth leads to an increase in $\mathrm{Ra}$. These results correspond to what was published in the research [6].

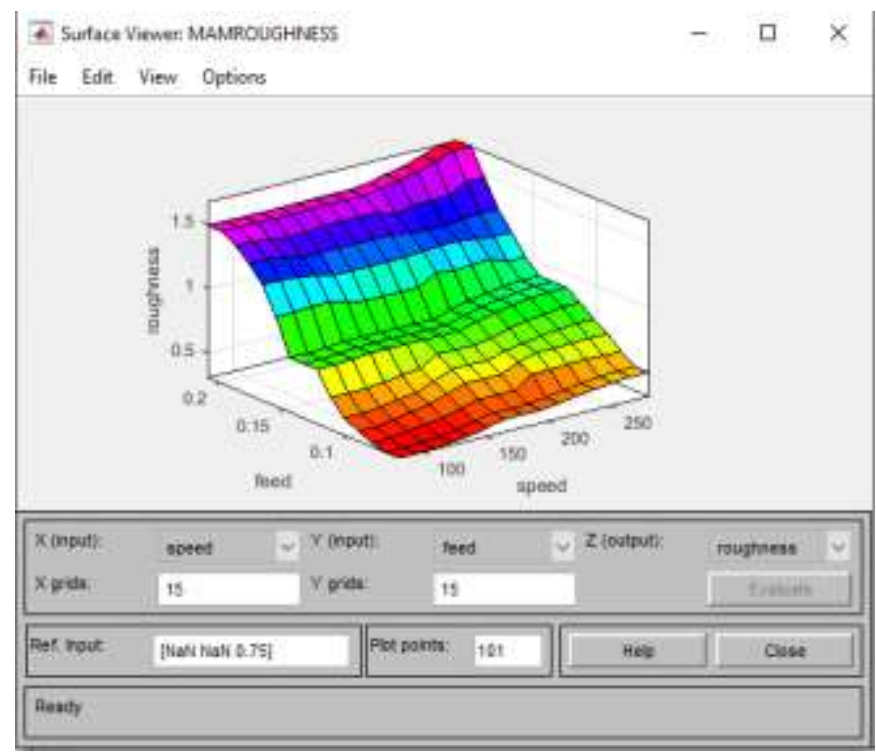

Fig .10(a) Viewer of FIS surface showing the effect of speed and feed on the value of Ra by the first method. 


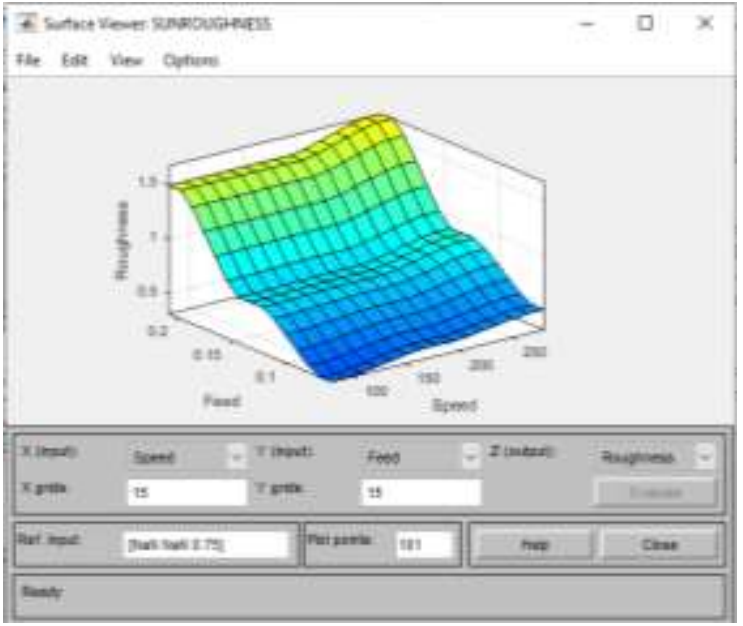

Fig .10(b) Viewer of FIS surface showing the effect of speed and feed on the value of Ra by the second method.

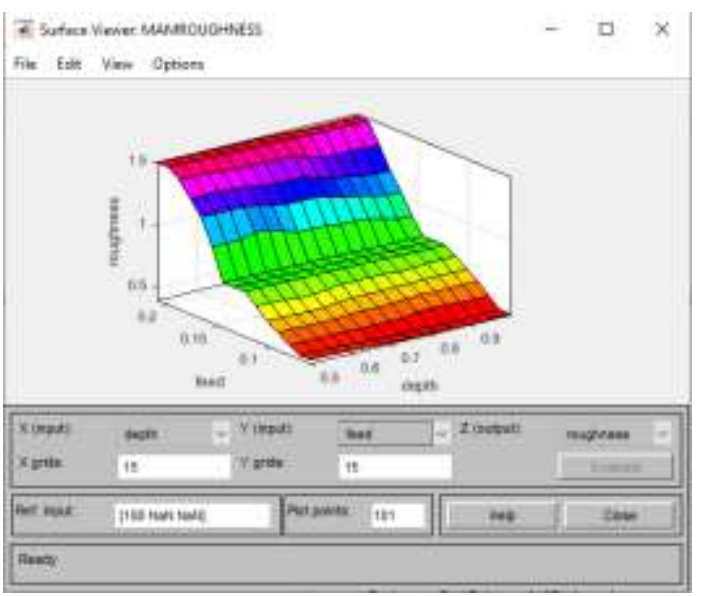

Fig 11(a) Viewer of FIS surface showing the effect of feed and cutting depth on the value of Ra by the first method.

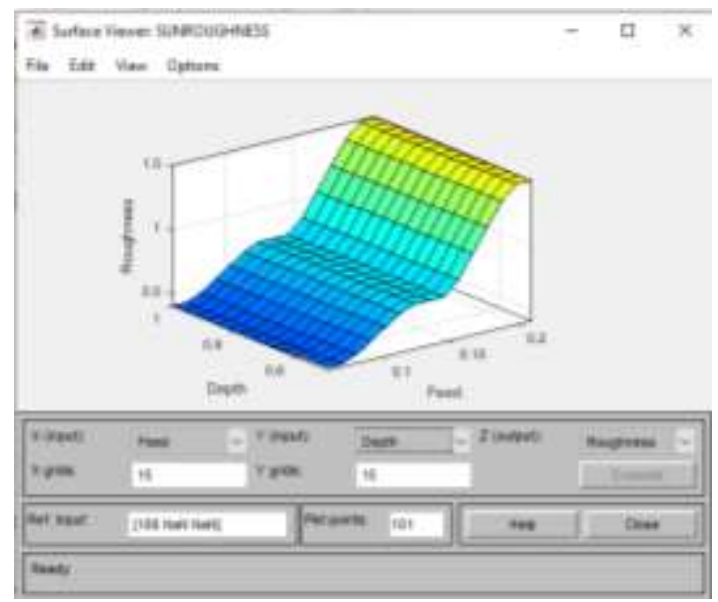

Fig 11 (b) Viewer of FIS surface showing the effect of feed and cutting depth on the value of Ra by the second method.

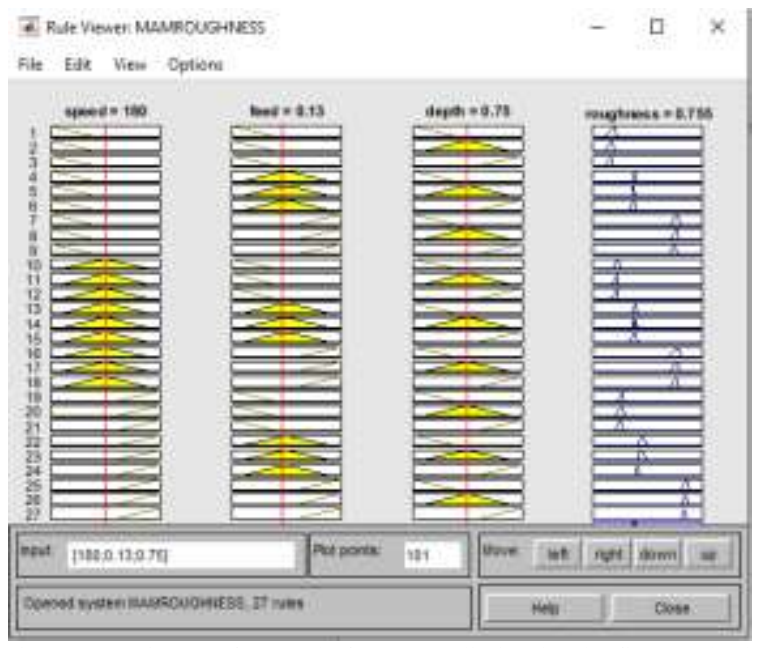

Fig. 12 (a) Viewer of FIS rule for Ra prediction by the first method.

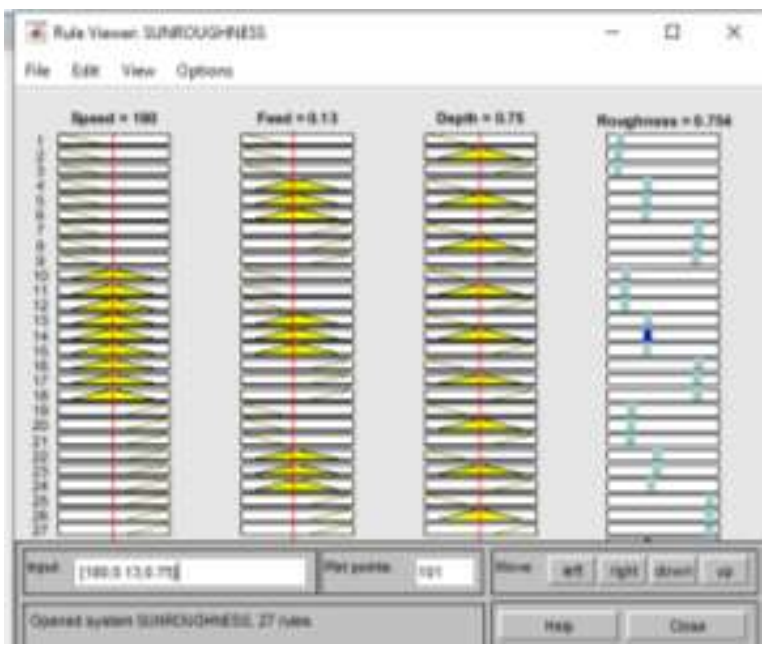

Fig. 12 (b) Viewer of FIS rule for Ra prediction by the second method. 
Table 3

Some predicted values of Ra in comparison with experimental \& theoretical (average) ones.

\begin{tabular}{|c|c|c|c|c|c|c|c|c|}
\hline No & $\begin{array}{c}\text { Cutting } \\
\text { speed } \\
(\mathrm{m} / \mathrm{min})\end{array}$ & $\begin{array}{c}\text { Feed } \\
(\mathbf{m m} / \mathbf{r e v})\end{array}$ & $\begin{array}{c}\text { Cutting } \\
\text { depth } \\
(\mathbf{m m})\end{array}$ & 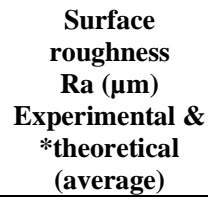 & $\begin{array}{c}\text { Surface } \\
\text { roughness } \\
\operatorname{Ra}(\mu \mathrm{m}) \\
\text { Predicted. } \\
\text { First method }\end{array}$ & $\begin{array}{c}\text { Surface } \\
\text { roughness } \\
\operatorname{Ra}(\mu \mathrm{m}) \\
\text { Predicted. } \\
\text { Second method }\end{array}$ & $\begin{array}{l}\text { Percentage } \\
\text { error using } \\
\text { first method }\end{array}$ & $\begin{array}{c}\text { Percentage } \\
\text { error using } \\
\text { second method }\end{array}$ \\
\hline 1 & 80 & 0.06 & 0.5 & 0.3390 & 0.339 & 0.339 & $0 \%$ & $0 \%$ \\
\hline 2 & $80^{*}$ & $* 0.06$ & $* 0.625$ & $* 0.3252$ & 0.32 & 0.325 & $1.6 \%$ & $0.06 \%$ \\
\hline 3 & 80 & 0.06 & 0.75 & 0.3114 & 0.311 & 0.311 & $0.12 \%$ & $0.12 \%$ \\
\hline 4 & 80 & 0.21 & 0.75 & 1.4932 & 1.49 & 1.49 & $0.2 \%$ & $0.2 \%$ \\
\hline 5 & 180 & 0.06 & 0.5 & 0.4302 & 0.431 & 0.43 & $0.18 \%$ & $0.04 \%$ \\
\hline 6 & $* 180$ & $* 0.06$ & $* 0.625$ & $* 0.4203$ & 0.422 & 0.42 & $0.4 \%$ & $0.071 \%$ \\
\hline 7 & 180 & 0.06 & 0.75 & 0.4105 & 0.411 & 0.41 & $0.12 \%$ & $0.12 \%$ \\
\hline 8 & 180 & 0.21 & 0.5 & 1.5076 & 1.5 & 1.51 & $0.5 \%$ & $0.15 \%$ \\
\hline 9 & 180 & 0.21 & 1 & 1.4892 & 1.49 & 1.49 & $0.05 \%$ & $0.05 \%$ \\
\hline 10 & 280 & 0.06 & 0.5 & 0.5037 & 0.503 & 0.504 & $0.13 \%$ & $0.06 \%$ \\
\hline 11 & 280 & 0.21 & 1 & 1.6687 & 1.66 & 1.67 & $0.5 \%$ & $0.07 \%$ \\
\hline 12 & 280 & 0.13 & 0.75 & 0.8873 & 0.887 & 0.887 & $0.03 \%$ & $0.03 \%$ \\
\hline 13 & $* 280$ & $* 0.13$ & $* 0.875$ & $* 0.8445$ & 0.846 & 0.845 & $0.17 \%$ & $0.05 \%$ \\
\hline 14 & 280 & 0.13 & 1 & 0.8017 & 0.801 & 0.802 & $0.08 \%$ & $0.03 \%$ \\
\hline
\end{tabular}

Note * refers to theoretical (average) values

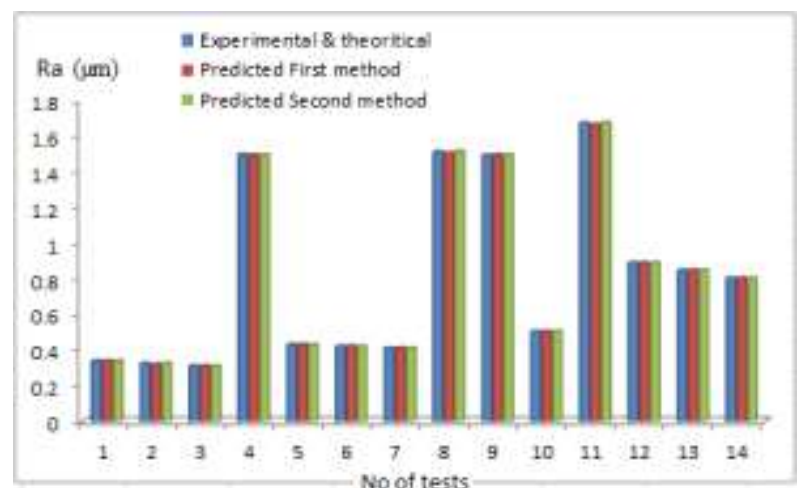

Fig.13 Graphical comparison between predicted value of $\mathrm{Ra}$ and the experimental \& theoritical (average) ones using the suggested fuzzy logic approach.

\section{CONCLUSION}

From what has already been presented about the previous two methods (Mamdani and Sugeno) which were used to construct the suggested model of fuzzy logic for predicting $\mathrm{Ra}$, it is possible to conclude that using of these methods gives good results and low percentage error as shown in Table 3 , also saves effort and time in predicting surface roughness values.

For the above case study, the second method (Sungeno) give better results comparing with first one (Mamdani) Table 3 and that depends on the nature of the outputs, inputs and the form of the relationship that binds them together, if the relationship between inputs and outputs variables are predicted to be as linear, it will be preferred to use Sugeno method.
The use of this suggested fuzzy logic approach is very important for both researchers and manufacturers to anticipate the intermediate values of surface roughness according to the different cutting conditions and vice versa without performing experiments depending on what has been done from previous practical experiments as this application works as an excellent database.

This fuzzy approach can be easily constructed, edited, and viewed in laboratories, especially laboratories for accurate measurements, to predict surface roughness, roundness, concentricity, run out, perpendicularity, flatness, etc. for any material under any conditions of cutting.

This application can help engineers to make the right quick decision during the manufacturing and assembling of products whose quality depends on knowing the degree of surface roughness.

\section{REFERENCES}

[1] P.G. Benardos, G.-C. Vosniakos, "Predicting surface roughness in machining: a review", 2003, 43, 883-844.

[2] E.S. Gadelmawla, M.M. Koura, T.M.A. Maksoud, I.M. Elewa, H.H. Soliman, "Roughness parameters" Journal of Material Processing Technology, 2002, 123, 133-145.

[3] Lütjering G., Williams J.C. "Titanium". Springer. 2 2nd ed. 2007, XII, 442.

[4] Imam M. A. "The 12th World Conference on Titanium Presents Research and Applications of "Wonder Metal"”, JOM., 2011, 63(10),1623.

[5] Khanna N., Sangwan KS. "Comparative machinability study on Ti54M titanium alloy in different heat treatment conditions". Proceedings of the Institution of Mechanical Engineers, Part B: Journal of Engineering Manufacture, 2012, 227(1), 96-101.

[6] KS Sangwan, S Saxena, Gkant, "Optimization of machining parameters to minimize surface roughness using integrated ANN-GA approach"Procedia Crisp, 2015- Elsevier.

[7] P.V.S. Suresh, P. Venkateswara, S.G. Deshmukh, "Agenetic algorithmic approach for optimization of surface roughness prediction model", 
International Journal of Machine Tools \& Manufacture, 2002, 42, 675680.

[8] Minggang Dong, Ning Wang, "Adaptive network-based fuzzy inference system with leave-one-out cross-validation approach for prediction of surface roughness", Applied Mathematical Modelling, 2011, 35, 9851550.

[9] YM Ali, LC Zhang, "Surface roughness prediction of ground components using a fuzzy logic approach", Journal of materials processing technology, 1999,90, 561-568.

[10] M. Brezocnik, M. Kovacic, M. Ficko, "Prediction of surface roughness with genetic programming", Journal of materials processing, 2004,157,28-36.

[11] P.G. Benardos, G.-C. Vosniakos, "Predicting surface roughness in machining: a review", International Journal of Machine Tools and Manufacture, 2003, 43, 755-862.

[12] S Kumanan, CP Jesuthanam, RA Kumar, "Application of multiple regression and adaptive neuro fuzzy inference system for the prediction of surface roughness", Int J Adv Manuf Technol, 2008, 35, 778-788.

[13] P Kovac, D Rodic, V Pucovsky, B Savkovic, "Application of fuzzy logic and regression analysis for modeling surface roughness in face milling", J Intell Manuf, 2013, 24, 755-762.

[14] Ramesh S., Karunamoorthy L., Palanikumar K."Measurement and analysis of surface roughness in turning of aerospace titanium alloy (gr5)", Measurement, 2012, 45, 1266-1276.
[15] Sivanandam.S.N, Sumathi.S, Deepa.S.N, "Introduction To Fuzzy Logic Using MATLAB", Springer, 2007

[16] D. Petrovic and A. Duenas, "A fuzzy logic-based production scheduling/rescheduling in the presence of uncertain disruptions", Fuzzy Sets and System, 2006, 157, 2273-2285.

[17] "Fuzzy Logic Toolbox'TM User's Guide", 13th Edition, The Math Works, Inc. Natick, US, 2008.

[18] G. A. Rastorguev; F. A. Elerian, "Spare Parts Management for the Repair of Machine Tools Using Fuzzy Logic Approach.”. MEJ. Mansoura Engineering Journal, 2014, 39 (2), 14-21.

\section{Title Arabic:}

$$
\text { التبؤ بخثونة السطح باستخدام نهج المنطق الضبابى }
$$

\section{Arabic Abstract:}

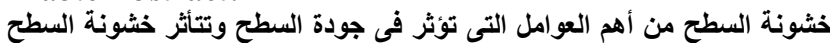

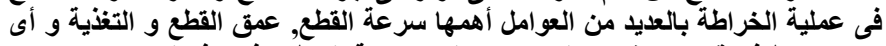

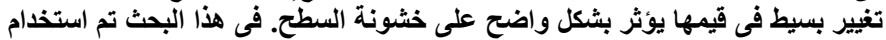

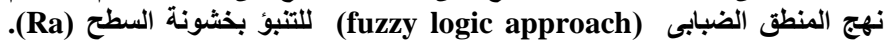

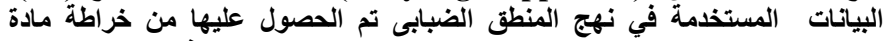

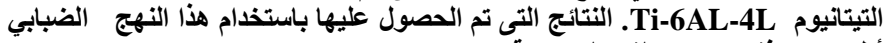
أظهرت توافقا جيدا مع القيم التجريبية. 